\title{
Cluster de serviços: \\ contribuições conceituais com base em evidências do pólo médico do Recife
}

Ana Cristina Fernandes Professora do Departamento de Geografia da UFPE e pesquisadora do $\mathrm{CNPq}$

João Policarpo R. Lima Professor do Departamento de Economia/PIMES da UFPE e pesquisador do $\mathrm{CNPq}$

\section{Palauras-chave \\ cluster, setor terciário, aglomerações produtivas, pólo médico, Recife.}

Classificação JEL R12, R19, D29.

Key words

cluster, service sector, production cluster, medical cluster, Recife.

JEL Classification R12, R19, D29.

\section{Resumo}

Analisar o setor terciário sob o enfoque de cluster constitui objeto pouco discutido na literatura. Tal análise consiste num desafio em si próprio, uma vez que o terciário envolve grande variedade de atividades, com especificidades em termos de trajetória e dinâmica de mercado que dificultam a generalização conceitual. O presente artigo pretende contribuir para essa análise, abordando a definição de cluster valendo-se da experiência do agrupamento territorial de empresas do chamado Pólo Médico do Recife. Interessa-nos verificar se os elementos conceituais que dão suporte à idéia de cluster podem também ter aplicação no setor terciário. Para isso, procuramos conciliar diferentes referenciais teóricos - a literatura sobre distritos industriais, transações econômicas e economia de inovação, todas focadas no setor secundário - com as especificidades do setor de serviços de assistência de saúde, objeto de nossa análise.

\section{Abstract}

Analysis of the service sector from the standpoint of clusters is not common in the literature. Such an analysis is a challenge in and of itself, since the service sector covers a broad range of activities, with different market dynamics and trajectories, making generalization difficult. This article seeks to contribute to this analysis, examining the definition of cluster based on the experience of the so-called Recife Medical Hub, a group of companies located in close physical proximity. We wanted to determine whether the elements on which the concept of cluster is based could also be applied to the service sector. To this end, we sought to reconcile different theoretical references: the literature on industrial districts, on economic transactions and innovation economy, all focused on the industrial sector, with the specifics of health care, the subject of this study. 


\section{1_Introdução}

O debate acerca do conceito de cluster no Brasil, assim como no plano internacional, tem suscitado o interesse de estudiosos e gestores de políticas públicas, desde que a prosperidade de aglomerações setoriais de pequenas e médias empresas em plena crise fordista, no início dos anos 1980, motivou revisitações às contribuições de Alfred Marshall sobre os distritos industriais. Impulsionada pelos conhecidos trabalhos de Porter (1990, 1998) sobre competitividade de firmas e regiões, e pelo reconhecimento por parte do mainstream do papel dos rendimentos crescentes para a dinâmica econômica nas chamadas novas teorias de crescimento e comércio internacional (Krugman, 1995), a importância da localização e a noção de cluster têm-se difundido tanto no campo acadêmico quanto no de formulação de política industrial em países de variada formação econômica. Sob a denominação de arranjos produtivos locais, os agrupamentos de pequenas e médias empresas vêm alcançando grande ressonância no Brasil, como atestam extensa produção acadêmica (Cassiolato e Lastres, 2001, entre outros) e fomento governamental (via Sebrae, especialmente).

A idéia subjacente ao conceito é a de que existe uma correlação entre porte e flexibilidade de adaptação às exigências da evolução constante da acumulação capitalista, e de que essa flexibilidade decorre em parte da divisão de trabalho alcançada em agrupamentos territoriais de empresas de uma mesma cadeia de valor. Daí a referência predominante a aglomerações de pequenas e médias empresas. Trata-se, em suma, da noção de externalidades derivadas de locações industriais especializadas, proposta por Marshall ainda no século XIX: especialização setorial e divisão de trabalho intensificam eficiência e competitividade da firma, induzindo à concentração espacial.

Em meio à crise de acumulação, nos anos 1980, são a flexibilidade e a concentração geográfica de firmas de pequeno e médio portes operando em setores especializados que vão chamar a atenção de pesquisadores de distintas tradições para os distritos industriais da chamada Terceira Itália, da região industrial do Sul da Alemanha e da França, e para os agrupamentos de alta tecnologia do Sun Belt norte-americano (Piore e Sabel, 1984; Scott, 1988; Aydalot, 1986; Becattini, 1991; Humphrey e Schmitz, 2002; Cooke e Morgan, 1998; Asheim, 1996; Maillat, 1996). Por outros caminhos, também se aproximam da dimensão espacial da competitividade industrial estudiosos da economia da inovação de inspiração evolucionista, especialmente com base no conceito de 
sistema nacional de inovação (Lundvall, 1992; Dosi, 1999; Freeman, 1995). A partir daí, a literatura em torno da noção de cluster tem-se adensado consideravelmente, ocupando espaço relevante até nas novas teorias de desenvolvimento.

No entanto, essa literatura tem derivado de observações empíricas concentradas no agrupamento de firmas do setor secundário. Embora mencionado por Porter (1998) como possível de ocorrer em qualquer segmento de atividade econômica, o cluster de serviços não tem recebido atenção tanto quanto seus congêneres industriais. Não surpreende tal comportamento, todavia, ao se considerar a grande diversidade de segmentos e respectivos mercados e estratégias competitivas e locacionais compreendidos no genérico setor de serviços, o que introduz dificuldades adicionais em termos de possíveis generalizações ou indicações de políticas públicas. Compreender a influência de clusters sobre a concorrência em mercados do setor de serviços constitui assim tarefa espinhosa, que, no entanto, começa inevitavelmente com a recuperação da literatura focada nos agrupamentos industriais.

Reconhecendo as dificuldades analíticas associadas à grande diversidade de segmentos inerente ao terciário, o presente artigo pretende contribuir para es- se esforço baseando-se no confronto da definição de cluster a um dado agrupamento localizado de empresas do segmento de prestação de serviços de atenção à saúde, o chamado Pólo Médico do Recife (PMR). Com o sentido de verificar a sustentação dos elementos conceituais que dão suporte à noção de cluster para o setor secundário, procuraremos primeiramente aprofundar a compreensão da noção de cluster de serviços, em geral. Em seguida, em vista da diversidade de situações internas ao setor de serviços, focaremos o segmento de serviços de saúde para destacar suas especificidades. Finalmente, consideraremos as particularidades de um cluster de serviços de saúde localizado em país de desenvolvimento retardatário.

Para tentar discutir essas questões, selecionamos referências de diferentes campos teóricos - a literatura sobre distritos industriais, economias de aglomeração e custos de transação e a chamada teoria evolucionista de inovação, todas igualmente focadas no setor secundário -, analisadas em contraposição às especificidades do setor de serviços de atenção à saúde, objeto empírico de nossa análise. A essas, contrapomos a literatura sobre rede urbana para compreender as especificidades do terciário mencionadas acima. Baseado em resultados de pesquisa 
que estudou um conjunto de segmentos do setor de atenção privada à saúde no Recife (Lima et al., 2004), o presente artigo está estruturado da seguinte forma: na seção 2 , retomamos aspectos conceituais gerais em torno da noção de cluster, a seção 3 é dedicada a uma reflexão sobre as condições para a concentração espacial de firmas industriais, apontando suas limitações ou adequações ao setor de serviços; em seguida, na seção 4, são feitas observações sobre clusters de saúde e suas especificidades; na seção 5 apresentamos breve histórico e caracterização do Pólo Médico do Recife, com base nos quais avaliamos a pertinência do arcabouço analítico esboçado nas seções anteriores. Finalmente, a última seção apresenta as considerações finais do trabalho, destacando as particularidades dos diversos segmentos de serviços e as determinações da formação socioeconômica sobre o fenômeno da clusterização.

\section{2_Aspectos conceituais sobre aglomeração de atividades econômicas}

Em que pese sua disseminada aceitação, não existe uma definição de cluster de aceitação geral. Ao contrário, o termo é usado indiscriminadamente para uma variedade considerável de arranjos de firmas ou negócios, que incluem desde o mais antigo conceito de distrito industrial até terminologias mais recentes, como arranjo produtivo local, milieu innovateur, sistema industrial localizado, sistema local de produção, tecido industrial local, ecossistema localizado, etc. Se de um lado tamanha diversidade de termos denota a própria fragilidade do conceito e a enorme dificuldade de exprimir diversidade igualmente expressiva de situações sob uma única concepção, por outro revela o crescente interesse de estudiosos pela análise de novas formas de industrialização localizada, abrindo oportunidades para se redescobrir e atualizar o trabalho de Alfred Marshall, como argumenta Maillat (1999).

Podemos dizer que, no seu sentido mais sumário, cluster denota simplesmente a concentração espacial de atividades econômicas setorialmente especializadas que realizam intenso comércio entre si, sentido este que, apesar de demasiadamente difuso, expressa a importância da dimensão espacial para o desenvolvimento econômico: clusters adquirem relevância porque desencadeiam efeitos externos e interação entre diferentes agentes localizados próximos uns aos outros. Além disso, esse padrão específico de produção associada ao território é reconhecido como formado preponderantemente por pequenas e médias empresas. No entanto, 
são características mais expressivas que têm atraído a atenção de estudiosos e governantes para o fenômeno da aglomeração produtiva: oportunidades para eficiência coletiva decorrentes de economias externas positivas, baixos custos de transação e ação conjunta e coordenada, como destaca Schmitz (1995).

Sob essa perspectiva, não poderia ser considerada como cluster uma simples concentração de agentes econômicos independentes ou aglomerações de coincidência, formadas ao acaso, como aquelas simplesmente atraídas pela gravidade metropolitana. É preciso bem mais que isso, e esse mais refere-se à intensidade das re-

$\begin{array}{ll}1 \text { Em On competition (1998), } & \text { agentes econômicos, políticos e } \\ \text { onde se encontra a conceituação } & \text { sociais, localizados em um mesmo } \\ \text { transcrita, Porter registra } & \text { território, que apresentam vínculos } \\ \text { contribuições de extensa e } & \text { consistentes de articulação, } \\ \text { variada literatura que havia sido } & \text { interação, cooperação e } \\ \text { desenvolvida ao longo dos anos } & \text { aprendizagem. Incluem não apenas } \\ \text { 1990, contribuições estas } & \text { empresas - produtoras de bens e } \\ \text { responsáveis pela evolução do } & \text { serviços finais, fornecedoras de } \\ \text { conceito para incorporar } & \text { insumos e equipamentos, } \\ \text { especialmente os aspectos } & \text { prestadoras de serviços, } \\ \text { sistêmicos e a dimensão da } & \text { comercializadoras, clientes etc. e } \\ \text { inovação para a competitividade } & \text { suas variadas formas de } \\ \text { das firmas e das aglomerações } & \text { representação e associação -, mas } \\ \text { especializadas. } & \text { também outras instituições } \\ 2 \text { Síntese proveitosa é sugerida } & \text { públicas e privadas voltadas à } \\ \text { por Suzigan et al. (2003, } & \text { formação e treinamento de recursos } \\ \text { p. } 40-41), \text { ao definirem clusters } & \text { bumanos, pesquisa, } \\ \text { como sistemas locais de } & \text { desenvolvimento, engenharia, } \\ \text { produção, isto é, "aglomerados de } & \text { promoção e financiamento". }\end{array}$

lações interfirmas que se realizam no interior da aglomeração, externas à firma, portanto. Essa idéia de interconectividade entre as partes componentes de um cluster é recorrente na literatura, assim como a evidência que essas partes não incluem apenas as firmas, mas também variadas instituições que lhes dão suporte.

A importância atribuída à interconectividade e à pluralidade de organizações e instituições para bem circunscrever a noção de cluster é aspecto central na literatura, ${ }^{1}$ presente em diferentes definições que vêm contribuindo para a evolução do conceito, embora partindo de diferentes motivações teóricas. Seja por focarem a competitividade das firmas e regiões (como destacam as novas teorias de crescimento e a chamada nova geografia econômica), seja por orientaremse pela importância da inovação para o desenvolvimento (como defendem as formulações de matriz evolucionista), seja pela dimensão institucional mais recentemente introduzida na teoria econômica (sustentada pelo chamado novo institucionalismo), a ênfase no caráter sistêmico e no papel crucial da troca de informações entre as partes que compõem o sistema são fatores hoje obrigatórios para o entendimento do fenômeno. ${ }^{2}$ 
A literatura é obviamente extensa e variada, ${ }^{3}$ mas, inegavelmente, podemos afirmar que o conceito evoluiu de forma substancial ao incluir fatores sistêmicos. No entanto, a compreensão da importância destes últimos envolve considerações acerca das razões que levam as firmas a se aglomerarem, como demonstra a concepção de Steinle e Schiele (2002, p. 850-851). Para esses autores, clustering ocorre por diversas razões:

_ porque um sistema de criação de valor se impõe desde o início do ciclo de vida de uma indústria;

_ a taxa de mortalidade das firmas localizadas em um cluster são menores do que na firma isolada;

_ a proximidade tende a promover negócios interrelacionados, que, por sua vez, favorecem especialização e a formação de redes, que, finalmente, são importantes instrumentos de troca de informações necessárias para a elevação da eficiência objetivada pelas firmas.

Conjunção entre especialização e eficiência, baixos custos de transação e diversidade, estimulam necessariamente divisão de trabalho, que constitui o manancial para a emergência do fenômeno. No entanto, como argumentam Steinle e Schiele, algumas indústrias não se aglomeram, o que leva a supor que existam condições de natureza do mercado e do processo produtivo de cada setor de atividade que favorecem ou bloqueiam a aglomeração e a associação de agentes econômicos em ambiente fortemente determinado pela concorrência própria das economias de mercado, conforme mostra a seção a seguir.

\section{3_Condições para a aglomeração}

É reconhecida a tendência de as atividades econômicas se agruparem territorialmente em alguns países, regiões ou localidades, ao invés de se distribuírem eqüitativamente ao redor do Globo, mas também é notório que nem todas elas se agrupam. Sendo assim, compreender o fenômeno do agrupamento ou aglomeração de atividades econômicas significa identificar as vantagens de uma firma estar localizada próxima de outras, ou seja, as vantagens da proximidade como fator central para sua competitividade. Desde Marshall, tais vantagens estão relacionadas, como já observamos, à redução de custos de transação decorrentes da intensificação da divisão de trabalho e do progresso técnico, mais facilmente promovida pela circulação de fatores e informação a curtas distâncias (fácil substituição de fatores, mão-de-obra especializada,
3 Ver síntese elaborada por Maillat (1999) e coletânea coordenada por Suzigan (1999). 
aperfeiçoamento contínuo dos métodos de trabalho e equipamentos, "surgimento de indústrias subsidiárias”, entre outros aspectos).

Detalhando a idéia, Steinle e Schiele (2002) defendem que a vantagem fundamental para a firma se estabelecer numa aglomeração reside na possibilidade de reunir, em um mesmo local, fragmentação estrutural na escala e competência adequadas. Dessa forma, a firma minimiza seus custos de transação porque, de um lado, o retorno satisfatório proveniente da troca intensiva de informações entre membros inibe o comportamento oportunístico e, de outro, ali encontra os parceiros necessários para transformar idéias em negócios e em inovações. Assim, as vantagens da proximidade não se restringem a custos de transporte e de substituição de fatores, mas incluem também troca intensiva de conhecimento numa atmosfera que denominam do tipo "clube": os membros têm ciência de sua participação num sistema, aderem a um conjunto de normas comuns, convenções que respeitam em troca de sua participação, sob pena de serem expulsos se assim não procederem, o que lhes subtrairá as informações acessíveis apenas aos membros do "clube". A idéia aqui é de que não é qualquer setor de ativida- de que se aglomera em uma região, mas, quando isso ocorre, estar fora da aglomeração leva a um "custo de periferia" incorrido pelas firmas que ficam de fora dela.

No entanto, mesmo em países ou regiões mais desenvolvidos, não se observam agrupamentos de firmas e instituições especializadas indistintamente em todos os setores de atividade. Condições adicionais têm de estar presentes para um cluster se constituir e desenvolver, as quais, como advertem os autores, podem ser divididas em duas categorias: condições necessárias e condições suficientes.

\subsection{Condições necessárias e condições suficientes}

As condições necessárias são assim denominadas porque se referem ao elemento original para a existência do cluster, a divisão de trabalho. São duas as condições necessárias, sendo a primeira delas a divisibilidade de processo. Para Steinle e Schiele (2002), é a divisibilidade técnica que permite especializações e, portanto, fragmentação do processo produtivo. De outro lado, a divisibilidade para ser usufruída requer a presença de massa crítica em termos de volume de negócios e de firmas, de modo a viabilizar o processo de fragmentação, ou seja, devem existir agentes operando em cada elo da cadeia de valor 
para propiciar competição saudável e aprendizagem mútua.

A segunda condição necessária, na percepção dos autores, é a transportabilidade de produto. Para eles, se um produto não pode ser transportado, a localização de seus fornecedores é determinada pela localização de seus consumidores, o que introduz limitações à dinâmica concorrencial. Se o cluster, para ser competitivo, deve submeter-se à concorrência, ele não se pode fechar num sistema autárquico; ao contrário, o produto em que se especializa o cluster tem de ser transportável, de modo a impelir constante qualificação do produto para enfrentar a concorrência com produtores de outras regiões e países. ${ }^{4}$

Os autores advertem ainda que as duas condições necessárias devem estar sempre presentes: um cluster pode ser esperado mesmo no caso de indústrias menos inovadoras, desde que nelas seja possível divisibilidade técnica de processo e que estejam abertas à concorrência externa. Se seu produto ou serviço não pode ser transportado, seu mercado tende a ser autárquico ou estável, o que reduz a importância das economias de aglomeração que as firmas buscam ao se agrupar. Trata-se, pois, de uma condição que reduziria as chances de uma aglomeração se desenvolver na sua ausência, restando à proximidade a função de apenas redu- zir custos tradicionais de transação, mera proximidade geográfica estática. Voltaremos a ela mais adiante.

As condições suficientes, em número de quatro, dizem respeito simultaneamente a cada firma individualmente e ao conjunto da aglomeração. São elas:

i. cadeia longa de valor;

ii. diversidade e complementaridade de competências;

iii. adaptação flexível à volatilidade do mercado;

iv. inovação em rede.

As duas primeiras condições estão intimamente relacionadas à divisão de trabalho. A existência de cadeia de valor longa obviamente abre maiores oportunidades para especialização e, por conseqüência, criação de outros negócios, base para a ampliação da divisão de trabalho. Como sabemos, a extensão da cadeia de valor é determinada tecnicamente, isto é, determinada pela natureza do processo produtivo específico a setor. No entanto, alertam os autores, existem diferentes quantidades ótimas de produto por atividade e diferentes lucratividades entre os segmentos, e este ótimo está associado ao fato de que em alguns casos é mais econômico adquirir capacidade adicional externamente que vender os próprios excedentes no mercado. Sendo assim, ao menos em $\cdots \cdots \cdot \cdots \cdot \cdots$

4 A abertura para o exterior é mencionada por vários autores como fonte valiosa de constante esforço inovador, crucial para impulsionar o progresso técnico, a competitividade e a evolução dos clusters. Em alguns segmentos de serviço, essa é uma condição ausente ou limitada, que será abordada na análise específica do setor mais à frente. 
parte, a internalização da cadeia de valor na aglomeração está condicionada à sua organização, ou seja, às estruturas formais e não-formais de coordenação dos diversos agentes especializados e complementares que compõem a aglomeração, não apenas depois, mas também antes de as firmas suprirem ou obterem seus componentes (tailor-made supplies). A coordenação desempenha papel relevante no desempenho do cluster, à qual retornaremos nas próximas seções.

A segunda condição suficiente, $d i$ versidade de competências, também relacionada à divisão de trabalho, é suscitada pelo entendimento de que quanto mais distintas as competências em uma cadeia de valor longa, mais desafiante se torna para uma única firma dominá-las todas, novamente, abrindo oportunidades para novos negócios e especialização. Sendo essas competências complementares, embora distintas, isso significa que as interações entre elas tendem a se tornar freqüentes e a envolver informações e recursos importantes, favorecendo o desenvolvimento de confiança entre os agentes envolvidos. Afinal, com o aumento da distância, aumentam na mesma proporção os custos e as distorções de transação (aí incluídos os custos de transporte) para a manutenção de interações densas e freqüentes, como sugere Granovetter (1973), acompanhando a linha de raciocínio das conhecidas teorias locacionais de tradição weberiana. Não é difícil verificar que a cadeia longa favorece o agrupamento, mas junto com ela introduz-se o problema de coordenar as diversas partes da cadeia, cada uma especializada em competências distintas e com interesses diversos.

A terceira condição, adaptação flexível à volatilidade do mercado, reflete uma das motivações que impulsionam pequenas e médias empresas a se aglomerarem, e possivelmente, a elevada ocorrência de clusters formados por empresas desses portes. A importância da localização espacial aumenta à medida que diminui o controle dos produtores sobre mudanças no mercado de seus produtos e sobre o tempo de atendimento da demanda, estimulando assim a constituição de uma rede de transmissão de informação entre os agentes econômicos e institucionais territorialmente próximos entre si e, portanto, um sistema multiorganizacional. Este último pode adaptar-se a tais mudanças mais rapidamente e a custos mais baixos, já que volatilidade e dinamismo tendem a acentuar-se com a aglomeração, em função da facilidade de circulação e acesso a informações estratégicas que a aglomeração propicia aos seus 
membros, sendo essas informações cruciais para a competitividade da firma e para sua sobrevivência no mercado.

No que se refere à derradeira condição, a inovação em rede como motor para a aglomeração, Steinle e Schiele (2002) percorrem caminho já sugerido há bastante tempo por Jacobs (1970). ${ }^{5}$ Não obstante essa interpretação pioneira, a relação entre inovação e localização não vai ser objeto de observação mais atenta na literatura sobre cluster senão bem mais recentemente, com as contribuições do enfoque dos milieux innovateurs e da economia evolucionista da inovação, que contribuíram significativamente para a compreensão do que seja e como pode evoluir um cluster, como já foi destacado. Valendo-se dessas contribuições, os fundamentos da competitividade e evolução em direção a patamares mais dinâmicos passam a ser relacionados em grande medida à sua capacidade inovadora. Por essa razão, a relação proximidade-inovação assume atualmente papel central nas explicações sobre o desempenho de tais agrupamentos, de modo que consideramos oportuno abordá-la de forma destacada, reconhecendo-a - ao lado de mecanismos de cooperação e coordenação como condição essencial para a evolução da aglomeração.

\section{2_ Condições para a evolução da aglomeração}

\subsection{1_Inovação}

Além da importância de economias pecuniárias de aglomeração para a constituição e o desenvolvimento de um cluster, é inegável a importância do progresso técnico. No entanto, até recentemente, foi a defesa da eficiência e da diversidade que prevaleceu no entendimento do fenômeno, ressaltando-se, por conseqüência, as externalidades pecuniárias que estimularam tantos autores (dos clássicos a Krugman (1995), passando pelos californianos Scott e Storper (1986) a valorizar as economias de aglomeração como fator explicativo para o desempenho das firmas localizadas em aglomerações.

Em que pese sua relevância, o lado da circulação da informação e da capacidade de aprendizagem como condição para agrupamento vem atraindo a atenção de analistas só mais recentemente, com base na análise da dimensão sistêmica e territorial do processo de inovação e do entendimento deste como função endógena do desenvolvimento econômico, especialmente com as contribuições pioneiras dos evolucionistas (Freeman, 1987; Dosi, 1988; Lundvall, 1992; Nelson, 1996) e dos teóricos do milieu innovateur (Aydalot, 1986; Maillat, 1999). ${ }^{6}$ Inspirados nas
.

Jacobs argumenta que a

inovação decorre da concentração de agentes, em dado território. Proximidade estimula interação, criatividade e inventividade, que se materializam em novas atividades econômicas: trabalho novo é adicionado a trabalho preexistente, num movimento de contínua evolução. Já no final da década de 1960, a autora observa a então emergente Rota 128 para destacar o papel da pequena empresa (trabalho novo) no desenvolvimento da inovação, mesmo aparentemente não interessada em qualquer idéia de distrito industrial, cluster ou especialização setorial. Seu foco de atenção é a cidade, que tem na inovação associada às trocas no mercado sua fonte mais relevante de crescimento.

\footnotetext{
6 Para uma sistematização crítica ampla e bem organizada das interpretações evolucionistas e dos meios inovadores, no contexto de uma revisão da literatura sobre a importância da localidade para a inovação tecnológica, ver Miglino (2002).
} 
interpretações schumpeterianas de desenvolvimento econômico, essas análises concebem a inovação como fator intrínseco à concorrência intercapitalista e, portanto, responsável pelo constante desequilíbrio que impulsiona os agentes econômicos. Ao mesmo tempo, reconhecem que a inovação é um processo coletivo e cumulativo, porque decorre da interação entre diferentes agentes com distintas competências que combinam habilidades para melhorar produtos ou processos existentes ou criar outros visando à competitividade das firmas.

Sendo processo coletivo e cumulativo, a inovação guarda nexos estreitos com a concentração espacial: tem como elementos centrais o aprendizado e a interação entre diferentes e numerosos agentes, que se beneficiam inegavelmente da proximidade geográfica, já que requer não apenas troca constante e direta de conhecimento entre agentes distintos e complementares, como também é função de códigos, práticas, valores, sanções sociais, relações de confiança entre sujeitos que premiam a geração e a difusão de novos conhecimentos práticos e conceituais. Mais que isso, como argumenta Storper (1997), apesar do progresso das tecnologias de informação e comunicação, a proximidade continua sendo crucial para as dimen- sões comunicativas, interpretativas, reflexivas e de coordenação das transações. Tais dimensões dão conteúdo às interdependências não comercializáveis promovidas por interações face a face entre os agentes, seus sistemas cognitivos e seu aprendizado conjunto. São elementos intangíveis, mas também apropriáveis, específicos e localizados que operam para facilitar ou inibir o processo de inovação, complementam Freeman e Soete (1997).

Se é assim, independentemente se a inovação for radical ou incremental, ou se a atividade estiver em formação ou for de tecnologia madura, é imperativo correlacionar inovação e aglomeração: a probabilidade de ocorrência de um cluster seria maior no caso de indústrias inovadoras em que tais dimensões e interdependências entre múltiplos atores com distintas competências são fatores essenciais de competitividade. Clusters mais abertos à concorrência externa e mais flexíveis a mudanças nos seus mercados tendem a contar com a inovação como fator central de competitividade e, conseqüentemente, estar em constante evolução. Sabendo que tais aspectos imateriais ou culturais de que depende a inovação são lugar-específicos, não custa deduzir que a produção e a difusão de conhecimento têm caráter territorialmente localizado. A 
aglomeração oferece as bases materiais de proximidade e diversidade, bem como os aspectos relacionais intangíveis de que a inovação se nutre e por meio dos quais informação e conhecimento fluem, culturas empresariais e posturas em relação ao trabalho e à produção são difundidas.?

\subsection{2_ Cooperação e coordenação}

Ao colocar ênfase em fatores como aprendizado, conhecimento e inovação, as interpretações mais recentes, especialmente aquelas filiadas à teoria evolucionista, aproximam-se simultaneamente da expressão espacial e desigual do desenvolvimento capitalista (Morgan, 2004). A distribuição desigual do acesso ou apropriação de tais fatores ajuda a compreender tanto a dinâmica que preside as aglomerações especializadas de firmas como as grandes variações que elas apresentam entre si. Sabemos que o desenvolvimento de novos produtos e processos exige a interação entre variados conhecimentos, sendo essa uma das características da atual fase do desenvolvimento capitalista. Tal complexidade de conhecimentos impulsiona as atividades inovadoras a se processarem em rede, por envolver a combinação de diferentes competências num ambiente multiorganizacional: instituições governamentais e associativas, organizações e atividades complementa- res, além das firmas. Efeito espacial da importância das externalidades derivadas desse sistema é a elevação do custo relativo de relocalização da firma e, portanto, das vantagens de permanência na aglomeração, à medida que as interações entre as firmas vão se tornando mais complexas, reduzindo em contrapartida as vantagens de localização em outras aglomerações em que essas estejam ausentes.

Como essa cooperação não está assegurada pela simples proximidade geográfica, sua ausência é um dos fatores para as variações regionais observadas, sendo, por isso, de fundamental importância a coordenação dos agentes do cluster para a construção das externalidades necessárias. Cooperação entre agentes econômicos, vale ressaltar, é fenômeno sujeito aos imperativos da concorrência, apenas minimizada quando divisão de trabalho e divisibilidade técnica de processo e, portanto, complementaridade estão presentes. Ainda assim, a cooperação pode encontrar dificuldades para ocorrer, como é o caso de aglomerações onde prevalecem grandes assimetrias de poder entre os agentes, e daquelas localizadas em economias retardatárias, ou especializadas em setores tradicionais ou de tecnologia madura ou intensiva em mão-de-obra. Essas aglomerações tendem a se concentrar em
Bell e Pavitt (1993) argumentam que a construção dessas relações e valores é fator decisivo de desenvolvimento. Tais autores apontam esforços do governo sul-coreano para construir culturas organizacionais e inovadoras nas empresas de seu país, enviando jovens profissionais para atuar temporariamente como funcionários de empresas norte-americanas. A idéia subjacente é a de que o conhecimento codificado que esses jovens adquirem em cursos formais no exterior não é suficiente para lhes abrir o acesso a informações e conhecimento que são eminentemente tácitos, compõem referências culturais, códigos e valores que são transmitidos pela convivência, compartilhados por um grupo particular, especialmente por meio de relações face a face. 
$\cdots \ldots \ldots \ldots$

8 As soluções tendem a ser importadas porque esse ambiente não incentiva o desenvolvimento de modelos e procedimentos próprios necessários para a solução de problemas tecnológicos e, conseqüentemente, a construção de habilidades e competências que impulsionam o progresso técnico, como argumenta Dosi (1988).

9 Para os autores, "where sanctions and trust are missing, a production system requiring deepening specialization and interdependent firms is unlikely to develop" (Schmitz e Nadvi, 1999, p. 1506). mercados em que o preço, em vez da inovação, é o fator crucial de concorrência. Tendem a ali prevalecer opções por estratégias tecnológicas baseadas em importação de tecnologia, associadas a comportamentos oportunísticos e baixos padrões educacionais e de renda. ${ }^{8}$ Estruturas econômicas de regiões ou nações menos desenvolvidas concentradas em atividades tradicionais desestimulam, desse modo, a ocorrência de aglomerações inovadoras por produzirem entraves ao processo de inovação, mesmo em aglomerações onde se encontram presentes as mencionadas condições de divisibilidade de processo, diversidade de competências e cadeia longa de valor. Por essa razão, não apenas muito mais freqüentes que as aglomerações inovadoras, as aglomerações motivadas por custos estáticos de transação são mais freqüentes nesses países e regiões retardatários ou especializados em setores menos dinâmicos.

Da mesma forma, a coordenação não acontece de maneira "natural" no curso de formação de uma aglomeração. Ao contrário, alguns clusters jamais conseguem atingir o grau de dinamismo promovido por essa equação virtuosa formada por divisão de trabalho, especialização, eficiência e inovação, pelo fato de não disporem de mecanismos de coorde- nação minimamente eficazes. E, quanto maior a cadeia de valor, maior a importância desses mecanismos, que, sem recursos institucionais e culturais favoráveis, não se constituem. Como argumentam Schmitz e Nadvi (1999), a transição de uma aglomeração baseada em custos de transação tradicionais para outra baseada em inovação não apenas não é processo trivial, como está condicionado por determinantes de ordem estrutural de difícil superação, relativos às características de mercado e de formação socioeconômica. A eficiência coletiva necessária para o cluster evoluir e crescer, defendem os autores, só ocorre na presença, de um lado, de redes comerciais com o mercado externo, que introduzam grandes desafios e impulsionem a inovação (a abertura para o exterior, mencionada anteriormente), e de outro, de confiança e sanções efetivas, que coíbam o comportamento oportunístico e favoreçam a troca e a cooperação. ${ }^{9}$

A forte correlação que Schmitz e Nadvi identificam entre cooperação e elevação do desempenho das firmas em clusters localizados em nações menos desenvolvidas os leva a defender que nesses clusters a atenção deve ser dirigida para promover ações conjuntas, intensificação de troca de informação e experiências entre as firmas, de modo a construir 
redes de cooperação, sabendo que esta - a cooperação - é seletiva, ou seja, não envolve a totalidade dos membros da aglomeração. Isso significa que, além das condições para agrupamento assinaladas anteriormente, a evolução do cluster envolve especialmente recursos organizacionais, exógenos à firma, isto é, mecanismos de cooperação e coordenação. Sendo assim, se a evolução do cluster não prescinde de mecanismos de coordenação, mesmo em casos em que a cooperação e a inovação ocorrem espontaneamente, ainda mais necessários são eles em casos em que esses recursos são escassos. Diante disso, merece destaque o papel de catalisador e mediador que o poder público pode desempenhar nessas situações, no sentido de reduzir as assimetrias e facilitar a cooperação, auxiliar na identificação e na superação de fragilidades e promover ações conjuntas no cluster, quando essas não se manifestam espontaneamente.

Em síntese, são de duas naturezas, embora complementares, as condições que operam para impulsionar a emergência e a evolução de agrupamentos geográficos de firmas, a saber: divisibilidade de processo (com massa crítica em volume suficiente para assegurar complementaridade e diversidade), de um lado, e inovação e mecanismos de cooperação e coordenação, de outro. Sendo as primeiras condições determinantes para o agrupamento das firmas, tenderão a se agrupar aquelas atividades cujas estratégias competitivas - que são específicas a cada segmento de mercado - sejam mais sensíveis às condições mencionadas. A evolução do agrupamento, no entanto, vai estar condicionada às capacidades inovadoras, cooperativas e de coordenação nele presentes.

\section{4_Aglomeração de serviços de atenção à saúde: algumas anotações específicas}

A análise das condições para a emergência e evolução de aglomeração de atividades econômicas deixa ver que a noção de cluster é perfeitamente aplicável ao setor de serviços, em que pese a menção mais freqüente às atividades terciárias como auxiliares à dinâmica industrial, esta, sim, núcleo duro ou fonte de geração e crescimento da aglomeração na maior parte dos estudos sobre o fenômeno. ${ }^{10}$ Assim como no caso da indústria, o que pauta o estudo de clusters de serviços é o recorte setorial, com base no qual as condições para aglomeração são verificadas, e pela análise dos determinantes da formação socioeconômica na qual o cluster está contextualizado. Existem, portanto, caracte-

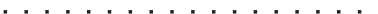

10 Porter (1998) menciona alguns clusters especializados em segmentos do setor de serviços (finanças, informática e turismo), embora esses sejam franca minoria no total dos clusters destacados naquele trabalho, nem sejam detalhadas suas especificidades. No entanto, na página eletrônica do projeto "Cluster Mapping Project", coordenado pelo autor, estão dispostos clusters de serviços registrados em diversos segmentos. Análise específica de tais clusters não está disponível para livre acesso na página do projeto (<http://secure.hbs.edu/ isc/; http://data.isc.hbs.edu/ isc/index.jsp $>$ ). Apesar desse mapeamento, julgamos insuficiente o nível de reflexão conceitual até aqui acumulado sobre o assunto. 
11 Entre os parâmetros adotados pelas autoridades estatísticas nacionais, entre as quais o IBGE, para a caracterização da hierarquia urbana em dado país ou região, estão justamente os serviços de assistência médica: nas cidades menores seriam encontrados os ambulatórios e os serviços mais simples, ao passo que nas metrópoles se encontrariam os segmentos de maior nível de especialização e complexidade, mais intensivos em recursos sofisticados. Ver IBGE/REGIC (1993). rísticas específicas que prevalecem sobre a constituição e o funcionamento de um cluster de serviços decorrentes do padrão de concorrência e estratégias locacionais desse setor, que inserem atributos particulares às condições de aglomeração e, por conseguinte, exigem atenção. Embora a abordagem recomendada seja a delimitação da análise por segmento do setor, que neste artigo é o de serviços de atenção à saúde, um esforço preliminar de generalização para o conjunto do terciário se faz necessário.

A observação das especificidades de um cluster de serviços pode ser facilitada a partir do entendimento dos fatores que concorrem para sua emergência. Entre esses, chamamos a atenção para o funcionamento dos estímulos relativos às economias de escala e ao acesso à informação e à idéia do "custo de periferia" para a dinâmica concorrencial de mercados do setor de serviços, segundo uma lógica de causação circular que impulsiona a aglomeração espacial das firmas, muito conhecida da economia regional (de Richardson, 1969; a Fujita; Krugman; Venables, 1999). Essa é uma tendência que afeta igualmente atividades industriais ou terciárias. No entanto, estamos aqui referindo-nos à tendência particularmente centrípeta de atividades terciárias em centros urbanos onde as economias ex- ternas funcionam como fator locacional por excelência. A prestação de serviços requer uma escala mínima para se estabelecer (mesmo simples serviços administrativos oferecidos por centros urbanos que servem apenas regiões rurais, como no modelo dos círculos concêntricos de Von Thünen (1826)). Tal escala, ou alcance espacial mínimo (demand threshold), expressa o menor número de consumidores necessário para economicamente viabilizar uma atividade.

Dessa forma, quanto mais sofisticadas as competências exigidas para a prestação do serviço e, portanto, maior a escala para viabilizá-lo comercialmente, maior a tendência a se localizar em níveis mais elevados da hierarquia de cidades as grandes aglomerações urbanas - onde economias externas e de escala são maiores e, conseqüentemente, maior é a força da "lógica circular". Essa percepção fundamenta a chamada teoria dos lugares centrais (Christaller, 1933; Lösch, 1940), baseia a identificação e a hierarquia de sistemas urbanos ${ }^{11} \mathrm{e}$ é especialmente válida para países de passado colonial e baixas interdependências na economia doméstica, cujas redes urbanas são bastante polarizadas por cidades primazes, como defendem Porter e Lloyd-Evans (1998).

Essa tendência à localização em grandes centros urbanos é fator decisivo 
para a competitividade das firmas dos segmentos mais complexos do setor de serviços. ${ }^{12}$ Isso quer dizer que a força de gravidade da metrópole atua no sentido de lhes proporcionar mercado na dimensão exigida para a realização de atividades mais intensivas em conhecimento e informação. Por outro lado, isso não quer dizer necessariamente que as atividades de serviços, que têm nas economias externas e de aglomeração um fator locacional relevante o bastante para neutralizar os custos de localização nessas cidades, busquem igualmente obter escala e capacidade para acessar mercados externos. Sua estratégia pode objetivar apenas o mercado metropolitano, grande o suficiente para a escala mínima necessária para o estabelecimento do negócio. ${ }^{13}$ Contudo, essa orientação para o mercado interno à sua área de influência pode significar limitação em termos de capacidade evolutiva para o cluster. Nesses casos cujo mercado é a metrópole e sua região, ${ }^{14}$ a concorrência com outras aglomerações metropolitanas tende a ser pouco expressiva, sendo a oferta de serviços quando muito complementar entre as várias metrópoles da rede urbana. Esse é o caso especialmente dos segmentos de serviços especializados cuja complexidade é elevada em relação àqueles oferecidos em sua região de influência, podendo não ser tão significativa em comparação àqueles oferecidos por metrópoles mais elevadas na hierarquia urbana.

Por outro lado, os segmentos cuja localização na metrópole é fator decisivo de competitividade (por ali encontrarem conhecimento e informação, mão-deobra qualificada e instituições educacionais e de pesquisa essenciais para suas estratégias concorrenciais), esses segmentos são os mais complexos e inovadores do terciário, à semelhança dos setores industriais que Tinoco (2001) chamou de urbano-dependentes. Trata-se de segmentos que não se localizariam em qualquer metrópole senão naquelas onde encontrem tais fatores, apesar das deseconomias de aglomeração. Dessa forma, são segmentos pouco representativos ou inexistentes nas metrópoles periféricas, visto que operam em mercados internacionais ou nacionais. Entre esses estão os segmentos mais sofisticados de serviços de finanças e seguros, instâncias de direção de grandes corporações, consultorias especializadas, informática, pesquisa e desenvolvimento, segmentos mais complexos de serviços educacionais, culturais e de atenção à saúde. ${ }^{15}$

Feitas essas considerações, observamos que tanto a condição de divisibili-
12 De fato, os clusters de serviços de atenção à saúde identificados nos EUA por Porter (2004) estão localizados nas principais áreas metropolitanas daquele país (os maiores estão em Nova Iorque, Chicago e Boston).

13 por essa razão, Porter classifica os clusters de serviços médicos de "locais".

$14 \mathrm{O}$ que se convencionou chamar de região de influência de uma cidade - ou alcance espacial máximo (maximum range threshold) nos termos de Christaller - é justamente definido pela distância que o indivíduo percorre entre sua residência e o mercado onde sabe que encontrará o bem ou serviço que procura, apesar dos custos de transporte que envolvem esse deslocamento. Quando o serviço é de altíssima especialização, a região de influência alcança distâncias consideráveis, como é o caso do tratamento de algumas enfermidades que levam pacientes a procurar atendimento em outras regiões ou mesmo países. 15 Com a globalização, vem-se acentuando a concentração de tais atividades terciárias mais complexas nas cabeças da rede urbana mundial, motivando Friedmann (1986) e Sassen (1991) a formularem a noção de cidade global. 
dade de processo quanto a de volatilidade de mercado são aplicáveis ao setor terciário, mas não a todos os seus segmentos, pelas razões apontadas. Um dos casos em que ocorrem as condições mencionadas é o do segmento de atenção à saúde. Esse é composto por um conjunto de atividades que operam em mercados interrelacionados com determinações próprias de funcionamento e concorrência, mas com intensa interdependência: o mercado de seguros de saúde, de clínicas de diagnóstico, o mercado de hospitais, de software para gerenciamento de atividades de saúde, serviços médicos de variadas especialidades, pesquisa médica, entre outros, restringindo-nos aos segmentos de serviço apenas de uma cadeia de valor bem mais extensa se incluídos os segmentos industriais, os serviços de formação profissional, informática e de pesquisa e desenvolvimento dedicados ao segmento.

No que concerne à volatilidade de mercado, podemos argumentar que, em termos genéricos, o segmento de serviços de atenção à saúde é um mercado com capacidade de ajuste a mudanças imprevisíveis na demanda, mas no interior desse existem grandes variações. Tomando o padrão tecnológico, podemos dividir o segmento em duas grandes categorias e observar as variações: uma cate- goria formada pelos segmentos usuários de equipamentos e instrumentos tangíveis (hospitais e clínicas de diagnóstico, por exemplo), e outra formada por atividades que fazem uso apenas de tecnologias de comunicação e informação, base material para atividades de natureza intangível (operadoras de planos de saúde e seguradoras, clínicas de especialidades médicas). Os segmentos da primeira categoria são particularmente mais dependentes de tecnologias produzidas por outros setores, geralmente desenvolvidas em países ou regiões avançadas. $\mathrm{Na}$ maioria dos clusters localizados em países menos desenvolvidos, a capacidade de ajuste às transformações nesses segmentos é reativa a trajetórias tecnológicas determinadas por grandes fornecedores globais de equipamentos médico-hospitalares e instrumentos de precisão, que chegam a condicionar até os procedimentos médicos. No caso dos segmentos da segunda categoria, as transformações são mais comumente associadas a variações conjunturais do nível de atividade econômica. Sua capacidade de inovação restringe-se a melhorias e à racionalização de processo e adaptações circunstanciais de produto para acompanhar as variações da demanda, especialmente em situações de desaquecimento da economia, com exceção das 
clínicas de especialidades médicas. Essas têm oportunidade de realizar constante progresso técnico em paralelo à evolução das ciências médicas. A pesquisa médica aqui representa fator central de dinamismo e competitividade.

Em vista das variações observadas, ainda assim é aceitável reconhecer que a condição de volatilidade no mercado está presente nos segmentos de serviços de saúde e, portanto, beneficia-se dos efeitos de aglomeração que tal volatilidade produz sobre os agentes desses mercados. Todavia, sabemos que a volatilidade é tanto mais significativa nos clusters localizados em níveis mais elevados da hierarquia urbana, como atua diferentemente sobre cada segmento da cadeia de saúde. Desse modo, serão tanto mais virtuosos os efeitos dessa volatilidade, quanto mais estímulos a capacidades inovadoras e cooperativas operarem no conjunto da aglomeração, no sentido de difundi-las dos segmentos mais aos menos dinâmicos da cadeia, de modo a reduzir paulatinamente a adoção reativa de soluções tecnológicas produzidas exogenamente, sejam essas soluções em termos de equipamentos e instrumentos médico-hospitalares, sejam essas em termos de procedimentos médicos.

A condição de transportabilidade de produto não pode ser aplicada tão direta- mente ao setor de serviços, em geral, nem aos segmentos de atenção à saúde, em particular. Como já mencionado, uma das características das cidades de posição mais elevada na hierarquia urbana é o fato de fornecer bens e serviços num nível de complexidade e diversidade que justifica grandes deslocamentos de consumidores. Isso é especialmente verdadeiro para o segmento de atenção à saúde, que exige a mencionada presença simultânea de médico e paciente para a prestação do serviço, apesar dos progressos nas tecnologias de transmissão de dados e imagens. Assim, a transportabilidade no caso do setor de serviços, em geral, e do segmento de serviços de atenção à saúde, em particular, é menos do produto, e mais do paciente, de modo que a competitividade da atividade é função da região de influência: quanto maior a distância percorrida pelo paciente em busca do serviço, mais abertas a mercados externos e mais competitivas são as atividades do cluster, que por definição são de maior especialização e complexidade, compensando o custo de transporte ou a distância econômica.

Em síntese, o setor é nitidamente concentrado em grandes centros urbanos e fortemente fragmentado, o que permite expressiva divisibilidade técnica de processo e diversidade de competên- 
cias distintas e complementares. Volatilidade de mercado e transportabilidade de produto manifestam-se de forma particular, podendo ser a primeira condição mais ou menos significativa, dependendo das capacidades inovativas e cooperativas ali presentes, e de estarem essas mais ou menos relacionadas ao uso de equipamentos sofisticados e de custo elevado ou à prestação de serviços de pequena especialização. É evidente que, quanto mais integrada horizontalmente a cadeia, articulando-se especialmente para trás com instituições de pesquisa e formação profissional e com setores industriais presentes na metrópole, desfrutando as externalidades ali presentes, maiores as probabilidades de evolução do cluster.

Cabe uma última nota específica aos mecanismos de coordenação no segmento de atenção à saúde. Por princípio, no espaço limitado de uma aglomeração geográfica, os custos de formação de mecanismos de coordenação são reduzidos, o que até funciona como fator de atração de novas firmas, apesar da fragmentação da cadeia de valor, do elevado número de firmas, das competências e instituições ali presentes. No cluster de serviços de saúde, a dificuldade de coordenação soma-se à forte propensão a conflitos entre os elos do seu núcleo duro, em razão da grande assimetria entre os elos da cadeia. É visível a posição determinante que desfrutam na cadeia as empresas de planos e seguros de saúde e hospitais (além dos fornecedores globais de equipamentos médico-hospitalares, considerando-se o escopo mais amplo). Ora, se como defendem Powell e Smith-Doerr (1994), a posição de um agente na rede, seu acesso a recursos e sua liberdade de ação estão diretamente relacionados a seu poder sobre o conjunto, sem coordenação, situações de monopólio de poder ameaçam a evolução da aglomeração.

A assimetria funciona como entrave à evolução do cluster, o que parece ser ainda mais verdadeiro no caso de clusters em economias retardatárias, por duas razões principais, ambas relacionadas com a fragilidade estrutural típica dessas economias: o padrão de financiamento de serviços de mais alto risco, valor e conteúdo tecnológico, e a precariedade dos sistemas de inovação local. Não é demais lembrar que essa precariedade limita a produção local do conhecimento necessário para o desenvolvimento de conhecimento (procedimentos médicos e de setores industriais, especialmente aqueles de equipamentos e instrumentos de tecnologia mais complexa ou de ponta, no caso do segmento em estudo). Decorre 
daí maior estímulo à importação de bens, o que restringe as oportunidades de negócios, eleva os custos operacionais das atividades, subordina estas às estratégias tecnológicas dos grandes fornecedores mundiais de equipamentos e afeta a formação dos profissionais. A superação desses entraves é um dos maiores desafios à coordenação do cluster. À vista dessas considerações, passamos à análise das especificidades do Pólo Médico do Recife.

\section{Evidências com base no Pólo Médico do Recife}

Antes de examinar a ocorrência no Pólo Médico do Recife (PMR) das condições para a formação de um cluster de serviços, vale recuperar rapidamente os contornos gerais de sua formação. O que se entende hoje pelo PMR é resultado de ações espontâneas de médicos com maior tino empresarial, que perceberam as oportunidades de mercado abertas com a expansão do modelo de saúde que prevalece no Brasil, onde o SUS cuida dos pacientes de baixa renda, enquanto o chamado sistema de saúde suplementar, privado, cuida dos que podem pagar planos e seguros saúde e/ou ser atendidos como clientes sem essa cobertura. Esse movimento tem origem na existência em Recife de certa tradição na área médica com a presença, há várias décadas, de grandes hospitais públicos e Faculdades de Medicina. Sendo um centro urbano de grande região de influência no Nordeste, Recife atraiu por muito tempo pacientes de localidades próximas e distantes por dispor de melhores condições relativas de atendimento.

Em fins dos anos 1980 e ao longo da década seguinte, em paralelo ao crescimento da medicina mercantil no País, as instituições privadas de saúde em vários segmentos foram sendo ampliadas no Recife, e muitos profissionais da área buscaram aperfeiçoamento em centros mais desenvolvidos do País ou do exterior, voltando depois para constituir equipes médicas e formar grupos econômicos com base em associações. Ao mesmo tempo, outros mais ousados empresarialmente obtiveram acesso a linhas de financiamento favorecidas dos bancos oficiais e, aos poucos, foram instalando hospitais, clínicas de diagnóstico e laboratórios de análises clínicas em moldes mais capitalistas e com maior preocupação em eficiência empresarial. Paulatinamente também foram chegando tanto operadoras de planos de saúde quanto fornecedores de insumos e de equipamentos mais sofisticados, o que vai ampliando o mercado, por um lado, e os padrões tecnológicos, por outro, definindo os contornos de um conjunto de empresas onde tais 
16 Verifica-se, mesmo assim, alguma interação entre o Pólo e algumas poucas empresas locais de equipamentos médicos relativamente sofisticados, que conseguiram se desenvolver na cidade aproveitando nichos de mercado e algumas competências de pesquisadores das universidades e de outras instituições locais.

17 Outras atividades profissionais incluem enfermeiras, nutricionistas, psicólogos, terapeutas ocupacionais e

fonoaudiólogos, fisioterapeutas, optometristas e outras similares, além de atividades de centros e núcleos de reabilitação e atenção psicológica, exercidas de modo independente, enquanto outras atividades relacionadas com a atenção à saúde compreendem atividades relacionadas a terapias não convencionais, serviços de ambulâncias, parteiras. fornecedores detêm poder relativamente elevado na definição de técnicas e de procedimentos. Ao adotar o modelo de procedimentos vigentes nos centros mais desenvolvidos, o PMR vai também simultaneamente optando por uma reduzida interação com as instituições locais de pesquisa e ensino, que lhe poderiam fornecer uma dinâmica tecnológica mais autônoma. ${ }^{16}$

\section{1_Características relevantes do Pólo Médico do Recife}

Antes de prosseguir, cabe salientar que o PMR apresenta alguns aspectos que atendem às condições para a aglomeração em cluster, sugerindo a pertinência da aplicação desse conceito ao segmento de serviços de atenção à saúde, sem, no entanto, atender a todas elas, como se poderia esperar. Isso não significa, contudo, que tais condições não possam vir a ser desenvolvidas, seja no caso específico em análise, seja em outras aglomerações de serviços de saúde. São fortes, contudo, as limitações à "evolução" do PMR em direção a um cluster inovador.

Uma primeira observação a fazer é que o PMR compreende um subconjunto de atividades que compõem o seu núcleo, e outro formado pelos elos com- plementares. O núcleo é constituído pelas atividades de:

i. atendimento hospitalar;

ii. atendimento de urgência e emergência;

iii. atenção ambulatorial;

iv. serviços de complementação diagnóstica ou terapêutica;

v. atividades de outros profissionais de saúde;

vi. outras atividades relacionadas com a atenção à saúde ${ }^{17}$ (Figura 1).

Entre os demais elos on atividades, destacam-se:

i. indústria farmacêutica;

ii. o comércio atacadista vinculado a medicamentos e equipamentos;

iii. o comércio varejista voltado para produtos farmacêuticos, artigos médicos e ortopédicos;

iv. financiadores e compradores de serviços (planos de saúde, fundamentalmente);

v. atividades de informática e produção de software;

vi. manutenção de equipamentos;

vii. atividades de formação de recursos humanos e de pesquisa;

viii. associações profissionais, empresariais e de classe. 


\section{Figura 1_ Serviços de saúde: estrutura e relações}

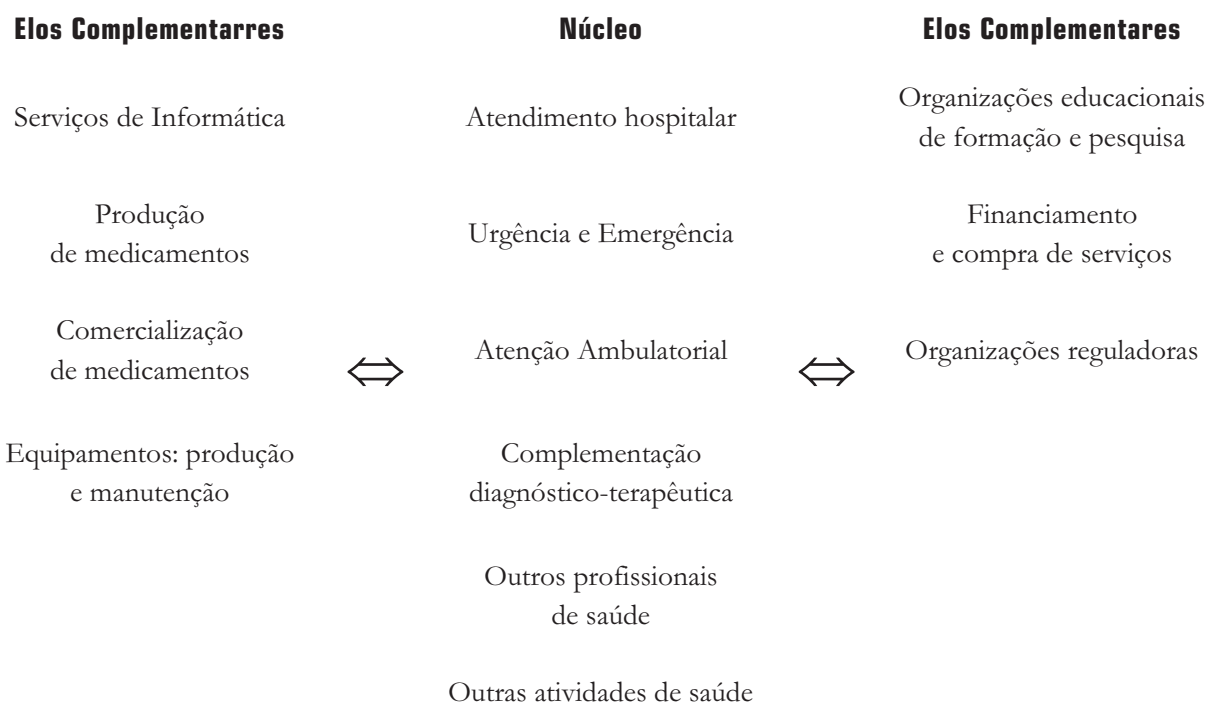

Fonte: Guimarães Neto et al., 2004.

Segundo os dados da RAIS, levantados pela pesquisa aqui referida, o núcleo do PMR empregava aproximadamente 20,2 mil pessoas em 2001 e abrangia cerca de 1,8 mil estabelecimentos. Incluindo-se os demais elos da cadeia, alcança-se um total de 34.715 pessoas formalmente ocupadas, vinculadas a 3.089 estabelecimentos. No núcleo do Pólo Médico, os serviços de atendimento hospitalar geram o maior contingente de empregos, seguidos dos segmentos de complementação diagnóstica e terapêutica e os de outras atividades de atenção à saúde. O emprego gerado pelo núcleo do Pólo, concentrado na cidade do Recife, correspondia a 2,2\% do total do emprego formal em Pernambuco, em 2001, e a $15,6 \%$ do emprego industrial formal. Considerando o total dos empregos do núcleo e dos demais elos da sua cadeia produtiva, chega-se a 3,6\% do conjunto do emprego formal em Pernambuco e a cerca de $1 / 4$ do emprego da indústria de transformação. São, portanto, números expressivos em termos de empregos e de estabelecimentos, que sugerem a ocorrência de expressiva divisão de trabalho, competências distintas e complementares e especialização, além de apresentarem razoável distribuição nos vários elos da cadeia, como mostra a Tabela 1. 
Tabela 1_ Recife: emprego formal e estabelecimentos nas atividades que integram o núcleo e os elos do Pólo Médico - 2001

\begin{tabular}{|c|c|c|c|}
\hline Atividades do núcleo e dos elos do Pólo & Emprego & Estabelecimentos & Empr./Estab. \\
\hline Indústria Farmacêutica & 815 & 27 & 30 \\
\hline Farmoquímicos & 141 & 4 & 35 \\
\hline Medicamentos para uso humano & 633 & 15 & 42 \\
\hline $\begin{array}{l}\text { Material para uso médico, hospitalar e } \\
\text { odontológico }\end{array}$ & 41 & 8 & 5 \\
\hline Comércio Atacadista & 1.298 & 126 & 10 \\
\hline Produtos farmacêuticos, médicos, ortopédicos & 1.016 & 92 & 11 \\
\hline Máquinas, aparelhos, equipamentos & 282 & 34 & 8 \\
\hline Comércio Varejista & 3.550 & 686 & 5 \\
\hline $\begin{array}{l}\text { Produtos farmacêuticos, artigos médicos } \\
\text { e ortopédicos }\end{array}$ & 3.550 & 686 & 5 \\
\hline Financiadores e Compradores de Serviços & 365 & 13 & 28 \\
\hline Planos de saúde & 365 & 13 & 28 \\
\hline Informática e Software & 1.566 & 143 & 11 \\
\hline Consultoria em sistema de informática & 394 & 43 & 9 \\
\hline Desenvolvimento de programas de informática & 349 & 43 & 8 \\
\hline Processamento de dados & 803 & 52 & 15 \\
\hline Atividade de bancos de dados & 20 & 5 & 4 \\
\hline Manutenção de Equipamentos & 263 & 52 & 5 \\
\hline $\begin{array}{l}\text { Manutenção e reparação de máquinas de } \\
\text { escritório e informática }\end{array}$ & 263 & 52 & 5 \\
\hline Organizações Educacionais e de Pesquisa & 5.071 & 155 & 33 \\
\hline Educação média e técnico-profissional & 1.196 & 35 & 34 \\
\hline Educação superior & 2.201 & 13 & 169 \\
\hline Educação continuada e aprendizado profissional & 1.674 & 107 & 16 \\
\hline
\end{tabular}


Tabela 1_ Recife: Emprego formal e estabelecimentos nas atividades
que integram o núcleo e os elos do Pólo Médico - 2001

\begin{tabular}{|c|c|c|c|}
\hline Atividades do núcleo e dos elos do Pólo & Emprego & Estabelecimentos & Empr./Estab. \\
\hline Núcleo do Pólo Médico & 20.162 & 1.809 & 11 \\
\hline Atendimento hospitalar & 11.674 & 139 & 84 \\
\hline Urgência e emergência & 315 & 17 & 19 \\
\hline Atenção ambulatorial & 809 & 358 & 2 \\
\hline $\begin{array}{l}\text { Serviços de complementação diagnóstica e } \\
\text { terapêutica }\end{array}$ & 3.255 & 316 & 10 \\
\hline Outros profissionais de saúde & 1.271 & 678 & 2 \\
\hline Outras atividades de atenção à saúde & 2.838 & 301 & 9 \\
\hline Associações Profissionais/Empresariais e de Classe & 1.625 & 78 & 21 \\
\hline Organizações empresariais e patronais & 1.246 & 27 & 46 \\
\hline Organizações profissionais & 379 & 51 & 7 \\
\hline Total & 34.715 & 3.089 & 11 \\
\hline
\end{tabular}

Fonte: Ministério do Trabalho e Emprego (RAIS-CAGED).

Como se pode observar na Tabela 1 , os serviços de atenção à saúde prestam-se bem ao fracionamento de atividades e à formação de especializações, o que é espelhado no PMR pela diversidade de ocupações existentes no núcleo do Pólo, que, por sua vez, demandam outras ocupações desencadeadas por esse, tanto no próprio setor terciário como na indústria. Essa, porém, desempenha papel de fornecedora de insumos para o núcleo do Pólo, em que pese a determinação de suas decisões estratégicas sobre a trajetó- ria tecnológica do agrupamento. Assim, como mostra o total do emprego formal no PMR, parcela significativa está ocupada nos serviços de complementação diagnóstica e terapêutica (basicamente laboratórios e clínicas de diagnóstico por imagem), nas atividades de "outros profissionais de saúde" e nas "outras atividades de atenção à saúde", entre outras. Também relevantes em termos de emprego no terciário no caso estudado, embora aqui definidas como atividades dos elos complementares, são os serviços de 

18 Algumas dessas atividades, vale referir, estão ainda em fase de consolidação como elos complementares, mas tendem a se afirmar à medida que as vantagens pecuniárias da divisão de trabalho forem se impondo. entidades educacionais e de pesquisa, o comércio varejista e atacadista de produtos e equipamentos médico-hospitalares, os serviços de informática, financiamento e venda de planos de saúde e a manutenção de equipamentos. Afora essas, ainda no terciário, também merece destaque a presença de atividades complementares de lavanderias especializadas, de fornecimento de alimentos, de fardamentos e rouparia, de recolhimento de lixo hospitalar, entre outras, que vêm ampliando seus contingentes em função da demanda das atividades do núcleo do PMR ${ }^{18}$ Fora do terciário, também marcam presença as atividades da indústria farmacêutica, gerando 815 empregos diretos em 27 estabelecimentos.

Outro aspecto associado a essa divisão de trabalho, ressalvadas as suas especificidades e as qualificações feitas anteriormente, é a predominância de um número elevado de estabelecimentos de pequeno porte, em geral associado aos conceitos de cluster já discutidos. Com exceção dos hospitais e estabelecimentos de ensino superior, que, mesmo assim, apresentam média próxima a 100 empregados, portanto não muito elevada, os estabelecimentos do Pólo contam com médias relativamente reduzidas de empregados, como também mostra a Tabela 1 .

\subsection{A dinâmica recente e o relacionamento entre os agentes e os segmentos}

Essa intensificação da divisão de trabalho no interior do PMR ocorreu preponderantemente ao longo da década de 1990, ao menos até 1998, quando o Pólo apresentou expansão considerável, traduzida em novos hospitais, laboratórios, centros de diagnóstico por imagem e clínicas médicas, ao lado da ampliação de fornecedores de insumos e serviços e até do surgimento de algumas empresas produtoras de equipamentos específicos. A razoável competência existente na área de C\&T no Recife e as janelas de oportunidade criadas com a intensificação de especialização expressa em desbravamento de nichos de mercado são fatores que ajudam a explicar a expansão. De maneira geral, ampliaram-se os investimentos na expectativa de aproveitar oportunidades então abertas por um mercado que se disseminava no País, e que, portanto, se apresentava com tendências de crescimento, tendo principalmente os usuários de planos de saúde como clientes.

Nesse ambiente promissor, muitos investimentos foram feitos em novas organizações e em aquisição de novos equipamentos, o que gerou expansão razoável de capacidade instalada no conjunto das instituições do Pólo. Ao final 
desse período, limitações estruturais começam a ameaçar essa expansão. Entre essas destacam-se a conjuntura de crise na economia, caracterizada pela estagnação do crescimento, a elevação do desemprego e a redução de salários reais, bem como as sucessivas desvalorizações do real. Em decorrência disso, estreitouse o mercado com a diminuição de usuários de planos de saúde (de 1,3 milhão para 800 mil pessoas, grosso modo), no mesmo momento em que as empresas de saúde defrontavam-se com a elevação de sua dívida por terem adquirido equipamentos com valores expressos em dólar. A combinação desses dois fatos tem trazido conseqüências preocupantes para o Pólo e colocado em risco a sobrevivência de parte significativa das organizações. De fato, já ocorreram desdobramentos nessa linha, com o fechamento de alguns hospitais, prenunciando-se dificuldades semelhantes em outros estabelecimentos do núcleo do Pólo.

Em vista das dificuldades postas pelo excesso de capacidade e pelo endividamento acima do planejado, as unidades do Pólo, em geral, têm recorrido a estratégias que envolvem tanto a ocupação de espaços mais amplos, diversificando, em alguns casos, os serviços prestados, quanto a prática de concorrência predatória via, por exemplo, negociação de tabe- las de preços com as operadoras de planos de saúde e estímulo, segundo alguns, a procedimentos mais diversificados de diagnóstico para gerar mais receitas, numa tentativa de transferir as dificuldades e se safar individualmente. Em outros casos, buscam também a articulação com profissionais médicos para a indicação de suas instalações para procedimentos cirúrgicos e de diagnósticos e ainda procuram atrair para seu negócio equipes médicas especializadas de competência reconhecida. ${ }^{19}$ Vale destacar que tais práticas terminam levando a conflitos e ao fechamento de unidades mais frágeis.

Nesse ambiente de dificuldades, os agentes com maior poder de barganha, ou seja, as operadoras de planos de saúde, buscam a sobrevivência, transferindo, sempre que possível, os encargos da sustentação do sistema como um todo, por um lado, para os usuários de planos via reajuste de mensalidades e, por outro, para os agentes subordinados, isto é, laboratórios, centros de diagnóstico, clínicas, profissionais liberais, etc., por meio do congelamento ou até da redução das tabelas de pagamento. Os hospitais maiores, com algum poder de barganha diante das operadoras, buscam negociações separadas e assim tentam viabilizar-se ou se manter à tona, financeiramente.

\author{
19 Foi comentado nas \\ entrevistas realizadas um \\ fenômeno conhecido em \\ escala nacional: em meio a \\ essa concorrência um tanto \\ acirrada, um grande hospital \\ do Pólo leva vantagens \\ adicionais, por ser \\ considerado beneficente e \\ desfrutar de menores encargos \\ previdenciários e tributários, \\ conseguindo ampliar suas \\ atividades em detrimento \\ dos demais.
}




\section{3_ Problemas, potencialidades e tendências}

O exame dos principais problemas do Pólo na percepção dos entrevistados ${ }^{20}$ revela razoável convergência de opiniões, nos vários segmentos analisados. Os problemas mais relevantes destacados são: excesso de capacidade instalada, com os rebatimentos de uma demanda insuficiente em cada um dos elos do núcleo e de concorrência acirrada e até desleal; hegemonia das operadoras de planos de saúde e dos grandes hospitais; carências de infra-estrutura; deficiência na formação de recursos humanos; carga tributária elevada; baixo nível de renda da população e, conseqüentemente, reduzido número de usuários de planos de saúde; baixa remuneração dos serviços prestados, que não permite a melhoria dos níveis salariais; dificuldades de acesso ao crédito; e elevado nível de endividamento de boa parte das unidades de saúde. Além desses problemas generalizados, são também mencionadas a concentração geográfica das unidades hospitalares; a concorrência crescente com os serviços de saúde de capitais próximas e cidades do interior, que antes enviavam mais pacientes ao Recife, com alguma perda de mercado; a carência de órgãos de representação de classe e a reduzida cooperação e concorrência com os serviços de saúde pública.
Quando se examinam as respostas às entrevistas sobre potencialidades e pontos fortes, observa-se também grande convergência e a concentração das potencialidades em aspectos intrínsecos das organizações, como a excelência dos serviços médicos oferecidos e a busca de capacitação por parte dos profissionais envolvidos; a estrutura física e tecnológica disponível; o espírito empreendedor da classe médica; a diversificação de serviços oferecidos; a localização privilegiada tanto do Recife na região Nordeste quanto do PMR num determinado bairro da cidade (Ilha do Leite); a geração de empregos diretos e indiretos, etc. Além desses aspectos, são também percebidos como pontos fortes a busca de certificação e de maior eficiência por parte das unidades privadas de saúde; a exclusividade de prestação de alguns tratamentos na região Nordeste; a credibilidade e a referência regional do Pólo, e ainda o suporte representado pelas competências de serviços de informática presentes na cidade. Essa última referência, embora só tenha sido feita em um dos segmentos do núcleo, é indício de que se percebe a necessidade de interação com os elos complementares da cadeia de valor.

Como se pode notar, esses são também fatores relacionados às condições para aglomeração destacados ante- 
riormente. Entretanto, em que pese a relevância dos pontos apontados como fortes e o razoável suporte que oferecem às atividades centrais do Pólo, é evidente que eles não asseguram por si sós capacidade de superação dos problemas existentes. Aliás, alguns dos pontos fortes apontados como a capacidade empresarial e a concentração de atividades foram, simultaneamente, listados como pontos fracos. ${ }^{21}$

Visto o panorama de problemas e potencialidades, vale examinar se as tendências em curso estão contribuindo para a solução de problemas e para o aproveitamento das potencialidades. Podemos antecipar que, pelo menos em parte, isso está ocorrendo. Entre as tendências mais mencionadas, encontram-se maior cautela na realização de investimentos, em vista do atual excesso de capacidade; descentralização das unidade na direção de outros bairros, inclusive para shopping centers, para atender melhor aos habitantes mais distantes da Ilha do Leite; concentração de serviços de diagnóstico, de análise clínicas e de atendimento clínico (consultas, por exemplo) nos grandes hospitais, pressionando a concorrência com essas unidades e apontando para a concentração de capital e verticalização no Pólo, na contramão das vantagens de es- pecialização para a aglomeração. No entanto, especialmente entre alguns elos específicos e unidades de pequeno porte, identificamos algum esforço incipiente de pesquisa (queimados, cardiologia, oftalmologia e traumatologia), melhoria dos procedimentos diagnósticos e terapêuticos, racionalização e especialização dos serviços, associação de pequenas unidade para enfrentar a concorrência e maior articulação com o Porto Digital. ${ }^{22}$

\section{4_Reflexões acerca das condições para aglomeração características do PMR}

Pelo que se pode apreender do exposto acima, o PMR apresenta algumas das condições para aglomeração destacadas na literatura comentada anteriormente, com as especificidades de ser especializado em serviços de atenção à saúde. Essa especialização particular parece não invalidar a possibilidade de que um cluster possa se formar, tanto no segmento específico estudado quanto em outros de prestação de serviços. $\mathrm{Na}$ verdade, alguns movimentos e características do caso aqui exposto permitem que se possa continuar defendendo a idéia de formação desse tipo de cluster, mesmo que apresentando especificidades inerentes às atividades terciárias, conforme segue.

\footnotetext{
21 Entre os pontos fracos foram mencionadas a administração familiar, que dificultaria a tomada de decisões, e a concentração de atividades na Ilha do Leite, que dificulta o acesso de pacientes de bairros mais distantes aos hospitais maiores em situações de emergência.

22 O Porto Digital é uma instituição fomentada pelo governo de Pernambuco e outras entidades públicas e privadas para estimular um cluster de serviços de informática no bairro do Recife Antigo.
} 
Por outro lado, reconhecemos que a ausência de condições de inovação em rede, cooperação e interação sinérgica entre seus participantes, se de um lado lhe retiram oportunidades de competitividade e dinamização, afetando sua trajetória tecnológica e seu próprio desenvolvimento, de outro, parecem não impedir completamente o processo de clusterização. Trata-se, porém, de um cluster específico de formação socioeconômica menos desenvolvida, em que são freqüentes conflitos entre os diversos segmentos, a polarização social repercute negativamente sobre a formação da mão-de-obra especializada, especialmente a de nível médio, e a natureza subordinada da dinâmica monetária e tecnológica limita a articulação com instituições de ensino e pesquisa e demais instituições públicas e privadas, o que poderia fortalecer e ampliar a cadeia de valor ali localizada. Senão vejamos.

A condição de transportabilidade, conforme tratado anteriormente, no caso de segmentos do terciário traduz-se no deslocamento dos consumidores de centros mais distantes para ser atendidos nas aglomerações metropolitanas. Nesse caso, o PMR sofre a concorrência de outros centros urbanos nordestinos, onde aos poucos vai se desenvolvendo a prestação de serviços de saúde, mas tem um raio de influência razoável no Nordeste, notadamente em algumas especialidades, como cardiologia, oftalmologia e em outros procedimentos que levam à obtenção de diagnósticos com base nos equipamentos sofisticados e na competência de seus especialistas.

Esse ponto, contudo, está a merecer atenção especial dos agentes do Pólo, uma vez que sua competitividade está condicionada, entre outros aspectos, à capacidade de seus agentes desenvolverem uma política de formação de especialistas de modo a torná-lo um centro de referência no Nordeste em determinadas especialidades. O deslocamento de grandes distâncias só se justifica pela obtenção de serviços de alta qualidade comparativamente àqueles prestados em outros centros regionais mais próximos do paciente, especialmente em situação de custos decrescentes de transporte. Isso porque as grandes distâncias em direção aos centros mais especializados do País são minimizadas, reduzindo o fluxo intra-regional. A capacidade do PMR de atrair pacientes de número mais expressivo de localidades da região, inclusive aqueles enviados por médicos que tenham desenvolvido sua formação no Recife, conforme sugere Sicsú (2004), decorre, assim, de constante qualificação de especia- 
listas, em particular, e da mão-de-obra empregada no setor, em geral. Por outro lado, a mencionada concorrência com outros centros regionais tem levado as empresas do Recife a investir em novos equipamentos e a tentar se distinguir dos concorrentes nos segmentos onde as escalas mínimas se impõem, embora essa concorrência não seja o único móvel de tais investimentos.

Com respeito à condição de diversidade de competências e fracionamento de atividades, essa pode ser identificada com maior facilidade no PMR. Isso porque o Pólo exibe, como vimos, várias especialidades médicas em diversas unidades de saúde e em níveis diferenciados de qualificação, além de estar aos poucos ampliando a divisão de trabalho com o surgimento de empresas especializadas em tarefas auxiliares do processo de prestação de serviços. Aqui se inserem tanto atividades que deixam de ser desenvolvidas nos hospitais e passam a ser terceirizadas (lavanderias e fornecimento de refeições, por exemplo) quanto outras ligadas aos procedimentos de saúde que vêm agregando novos profissionais e especialistas, os chamados profissionais $\mathrm{pa}-$ ra-médicos e até mesmo outras como transportes, alojamentos, limpeza e higienização e manutenção de equipamen- tos, entre outras. A continuidade desse processo de divisão de trabalho tenderá a contribuir para redução de custos e melhoria da qualidade geral do atendimento prestado aos pacientes. Essa diversificação, contudo, não vem sendo acompanhada dos mecanismos de coordenação necessários para minimizar os conflitos inerentes a uma cadeia de valor longa e especialmente assimétrica como essa. As estratégias de coordenação observadas são bastante incipientes ou exógenas, como aquela exercida pela Agência Nacional de Saúde, que tem contribuído para atenuar os conflitos nas relações entre planos de saúde e seus usuários e entre aqueles e os prestadores de serviços.

Pelos depoimentos coletados nas entrevistas, pode-se dizer que há no PMR manifestações da condição de adaptação à volatilidade do mercado. Afora as óbvias adaptações ante os reveses de mercado manifestadas no fechamento de algumas unidades, observam-se também deslocamentos de algumas unidades para bairros de periferia ou para o de Boa Viagem, ponto de concentração de população de renda mais elevada, havendo também a abertura de clínicas populares, para atrair clientes de renda mais baixa fora do mercado de planos de saúde. Outros movimentos de adaptação detectados com- 
preendem a organização, por iniciativa de hospitais de médio porte, de uma central de compras com o objetivo de reduzir custos de aquisição de insumos, ou a implantação de clínicas e ambulatórios por parte de empresários que contratam os profissionais de saúde para prestar serviços, principalmente consultas e exames, ou ainda a política de algumas unidades hospitalares maiores de atrair médicos mais conceituados para instalar consultórios no interior de suas dependências, objetivando com isso garantir reciprocidade em termos de realização de exames ou encaminhamentos para execução de procedimentos que exigem hospitalização. Trata-se, entretanto, de adaptações de caráter reativo, incapazes de determinar novas estratégias tecnológicas e empresariais; isso mostra as limitações inovadoras do PMR, o que já era sugerido na discussão conceitual feita anteriormente.

Tal condição de inovação como pré-requisito para aglomeração, contudo, merece algumas considerações. Conforme já adiantado, as grandes variações entre os segmentos do setor terciário refletem as diferentes capacidades de inovação existentes no setor de saúde, e, portanto, de resposta às vantagens de aglomeração determinadas pela inovação em rede. Enquanto o segmento de clínicas de diag- nóstico constitui-se preponderantemente de usuários de inovação desenvolvida por outros setores de atividade, o que faz dele um segmento de baixa capacidade de inovação, mesmo de processo, o segmento de hospitais pode estimular a inovação em termos de procedimentos médicos e no processo de trabalho e gestão da atividade como um todo, apesar de ser também um usuário de inovação produzida por terceiros. Já no segmento de planos e seguros de saúde, a inovação consiste basicamente na identificação de produtos que permitam a ampliação do leque de clientes considerando coberturas e faixas de renda, e na racionalização de gastos operacionais. Trata-se, assim, de um setor em que não se pode dizer que o conteúdo da inovação represente nem o mesmo dinamismo, nem que desempenhe papel relevante para todos os segmentos da aglomeração. No caso específico de uma formação socioeconômica tardia como essa em que está estabelecido o PMR, fica evidente a baixa importância da inovação como fator de aglomeração especialmente em alguns segmentos. A estratégia tecnológica adotada foi a de aquisição de equipamentos e adoção de procedimentos em sua maioria desenvolvidos em outros centros do País ou do exterior, muitos dos quais inconsistentes com a 
estrutura de renda e com o contexto macroeconômico ali prevalecentes.

Mesmo assim, existem sinais de algum esforço de superação ao menos de parte de tais limitações, possivelmente associados à base de ciência e tecnologia constituída no Recife. Há ali razoáveis competências tecnológicas acumuladas nas universidades e nos institutos de pesquisa locais nas áreas de biologia, física, engenharias e informática capazes de desenvolver produtos específicos para uso nas unidades de saúde. De certo envolta em severas dificuldades, essa competência parece estar se traduzindo na criação de empresas produtoras de tecnologia desenvolvida localmente, que têm o PMR como seu mercado, mas que vão além dele e vendem para outros centros do País. Embora ainda incipiente, essa interação com os institutos de pesquisa já é perceptível e tende a se ampliar particularmente no caso da área de computação, com a generalização do uso de aplicativos de microinformática. Por outro lado, observa-se também por parte das universidades e de alguns de seus grupos de pesquisa maior interesse em interagir com o Pólo Médico, seja na área de formação de profissionais mais dirigidos às várias áreas e especializações médicas, seja no desenvolvimento de outros produtos, pro- cedimentos ou competências para suporte e manutenção de equipamentos adquiridos de fornecedores externos. ${ }^{23}$

\section{6_Considerações finais}

Ao longo deste trabalho fizemos um esforço conceitual para melhor compreender o fenômeno da clusterização, destacando suas condições necessárias (divisibilidade do processo produtivo com massa crítica e transportabilidade do produto) e suficientes (cadeia longa de valor, diversidade e complementaridade de competências, adaptação flexível à volatilidade do mercado e inovação em rede). Realçamos o papel da inovação em rede como elemento aglomerativo, em que a abertura à concorrência externa e a difusão do conhecimento, tácito e codificado, jogam um papel preponderante, enquanto a cooperação e a coordenação entre agentes da cadeia de valor são elementos estratégicos e imprescindíveis ao pleno aproveitamento das vantagens de aglomeração.

O estudo de caso do Pólo Médico do Recife permitiu observar que, além de aspectos relativos às especificidades do mercado do setor terciário, a divisão de trabalho e a natureza própria da distribuição espacial das atividades de prestação de serviços são fatores fundamentais pa-
-

23 A UFPE, por exemplo, acaba de criar um curso de graduação em Engenharia Biomédica, reunindo conhecimentos de medicina, biologia, eletrônica, informática e física, entre outros. Entre os objetivos do curso, estão a formação de pessoal qualificado e o desenvolvimento de pesquisas focadas nos problemas tecnológicos do Pólo Médico, além da prestação de serviços diversos na área tecnológica. Com isso pode vir a ser reduzida outra lacuna observada atualmente, ou seja, o relativo isolamento intramuros dos grupos de pesquisa das universidades, que têm também sua contrapartida no segmento empresarial que até aqui pouco pela interação com a Universidade. 
ra a compreensão de tais agrupamentos de firmas. De um lado, a evolução do cluster de serviços está associada à capacidade de articular-se de forma sistemática com elos de outros segmentos do setor de serviços e com outros setores de sua cadeia de valor, especialmente o setor industrial, extrapolando os limites do terciário. De outro lado, o terciário apresenta distribuição espacial particular a cada segmento, concentrada nos níveis mais altos da rede urbana, o que impõe exigências de proximidade entre clientes e fornecedores com repercussões relevantes para a eficiência das firmas e a competitividade geral do conjunto. Essa espacialidade pode bloquear a abertura do cluster à concorrência externa e, portanto, limitar sua capacidade de reação a mudanças de paradigma, de constante aprendizagem e de identificação de fragilidades decorrentes de processos e culturas locais que dificultam o progresso técnico e trajetórias de desenvolvimento mais consistentes. Conseqüentemente, as condições para a concentração espacial de firmas do terciário apresentam características próprias ao setor, indicando a ocorrência de determinações específicas na formação e na evolução de clusters de serviços.

O exame dessas características permite inferir que a noção de cluster é aplicá- vel ao setor de serviços, desde que se atente para atributos particulares de cada um dos seus segmentos. Aqui, há que se ter em conta a tendência centrípeta de atividades terciárias em centros urbanos, onde as economias externas se impõem como fator locacional pelos requerimentos de escalas mínimas, mas também de maior intensidade de conhecimento e qualificação de mão-de-obra. A não-observância desses fatores contribui para restringir a clusterização em alguns segmentos de serviços. No caso dos serviços de saúde, a concentração locacional com maior densidade é dependente de escalas mínimas atingíveis em centros maiores, mas esse é um dos casos em que ocorrem as condições gerais de aglomeração, como divisibilidade e volatilidade do mercado. Esta última condição, entretanto, nem sempre é atendida, ou é atendida em parte, em países menos desenvolvidos, já que os padrões tecnológicos do setor e os protocolos médicos são determinados nos países ou regiões mais avançados. A condição de transportabilidade, por outro lado, não é facilmente verificável no terciário e particularmente na atenção à saúde. Devemos ainda lembrar que são variadas também as possibilidades de integração da cadeia de saúde com instituições de apoio e setores in- 
dustriais, o que, sendo aproveitado, pode elevar as probabilidades de evolução de clusters na área.

Todavia, pode-se concluir também que a ausência ou menor influência da inovação em rede não inviabiliza a aplicação do conceito ao setor terciário, mas requer sua qualificação. As condições específicas de uma formação socioeconômica tardia tendem a restringir a "evolução" do cluster de serviços e ainda assim é possível se observar nele elementos aglomerativos que mobilizam os agentes econômicos a se concentrarem territorialmente. Esses estão associados à redução de custos de transação, aí incluídos mecanismos de circulação de informação entre os membros da aglomeração.

A natureza dinâmica do processo inovador se traduz na constituição de competências tecnológicas pelas empresas por meio de um processo que envolve aprendizado e acumulação de conhecimentos, que encontram barreiras significativas nas estruturas da economia e da sociedade. Assim, a inovação mais observada no PMR resulta da introdução de modelos e equipamentos importados dissociada de avaliação de oportunidade. São evidentes os indícios de subordinação a determinações externas, investimentos equivocados, redução de taxa de retorno, ociosi- dade de investimento realizado e concorrência predatória, apesar da existência de alguns casos de cooperação e articulação com a base local de C\&T. Isso porque interações e propósitos estritamente comerciais e de curto prazo, relacionados a padrões rentistas historicamente atuantes na sociedade local, combinados com a busca por redução de custos e baixo prêmio à inovação, são inegavelmente fatores motivadores da configuração do PMR.

Por isso, tomando como referência o PMR, avaliamos que os desafios impostos para clusters em economias retardatárias - sejam do setor secundário, sejam do setor terciário - são muito elevados. Nada trivial, por exemplo, é construir nessas economias competências para reagir com inovação às mudanças inerentes aos mercados voláteis, propensos a crises cíclicas, em que a concorrência é baseada em tempo de resposta a desafios (time sensitive markets), bem como prestar atenção a mudanças de trajetória tecnológica (de processo e produto) e se qualificar para alcançá-las de forma sustentável.

Mais ainda, se é verdadeiro que a motivação para extrapolar a simples proximidade geográfica depende do reconhecimento da inovação como componente central da aglomeração de serviços, da firma individualmente e do conjunto, é 
fundamental reconhecer que suas possibilidades de evolução estão associadas a dois outros desafios. O primeiro é a superação de eventuais resistências culturais locais que desprezem bloqueios aos processos inovador (ausência ou limitação dos mecanismos de cooperação e coordenação, grandes disparidades de renda e educação, concorrência predatória). Superar tais resistências pode desencadear a construção de visão de conjunto, que não é apenas a soma das partes componentes, mas a base para a redução da assimetria entre essas e para a promoção das externalidades positivas e da interação entre as competências distintas e complementares presentes na cadeia de valor. O segundo é a abertura à concorrência externa e a interações com outros setores e segmentos da cadeia de valor para além dos segmentos do terciário que constituem seu núcleo duro original, esteja ele localizado em economias mais ou menos desenvolvidas. 


\section{Referências bibliográficas}

\author{
ALTENBURG, T.; Meyer-Stamer, \\ J. How to promote clusters: policy \\ experiences from Latin America. \\ In: WILSON, Suzigan (Coord.). \\ Clusters e sistemas locais de inovação: \\ estudos de casos e avaliação da \\ região de Campinas. Campinas, \\ Unicamp/Pró-Reitoria de \\ Extensão e Assuntos \\ Comunitários, 1999.
}

ASHEIM, B. Industrial districts as 'learning regions': a conditions for prosperity? European Planning Studies, n. 4, p. 379-400, 1996.

AYDALOT, P. Milieux innovateurs en europe. Gremi: Paris, 1986.

BECATTINI, G. Italian industrial districts: problems and perspectives. International Studies of Management and Organisation, n. 21, p. 83-90, 1991.

BELL, M.; PAVITT, K.

Technological accumulation and industrial growth: contrasts between developed and developing countries. Industrial and Corporate Change, v. 2, n. 2 , p. 157-210, 1993

CASSIOLATO, J. E.; LASTRES H. Arranjos produtivos locais e as novas politicas de desenvolvimento industrial e tecnológico. Rio de Janeiro: UFRJ/IE/REDESIST, 2001. Notas técnicas. mimeo.
CHRISTALLER (1933) apud JOHNSTON, R.; GREGORY, D.; SMITH, D. (Eds.). The dictionary of buman geography. [S.1.]: Blackwell, 1994.

COOKE, P.; MORGAN, K. The associational economy: firms, regions and innovation. Oxford: Oxford University Press, 1998.

DOSI, G. Sources, procedures, and microeconomic effects of innovation. Journal of Economic Literature, v. XXVI, p. $1120-1171,1988$.

DOSI, G. Some notes on national systems of innovation and production and their implications for economic analysis. In: ARCHIBUGI, D.; HOWELLS, J.; MICHIE, J. (Eds.). Innovation policy in a global economy. Cambridge: Cambridge University Press, 1999. p. 35-48.

FREEMAN, C. Technology policy and economic performance: lessons from Japan. London: Frances Pinter, 1987.

FREEMAN, C. The national system of innovation in historical perspective. Cambridge Journal of Economics, n. 19, p. 5-24, 1995.

FREEMAN, C. E.; SOETE, L.

The economics of industrial innovation. London: Frances Pinter, 1997.
FRIEDMANN, J. The world city hypothesis. Development and Change, v. 17, n. 1, p. 69-84, 1986. FUGITA, M.; KRUGMAN, P.; VENABLES, A. The spatial economy: cities, regions, and international trade. Cambridge, Ma: Mit. 1999.

GRANOVETTER, M. the strength of weak ties. American Journal of Sociology. v. 78, n. 6 , p. 1360-1380, 1973.

GUIMARÃES NETO et al. Dimensão e significado do Pólo Médico do Recife. In: LIMA J., Policarpo (Coord.) et al. O Pólo Médico do Recife: cadeia de valor, desafios e oportunidades. Recife: Editora Universitária da UFPE, 2004.

HUMPHREY, J.; SCHMITZ, H. How does insertion in global value chains affect upgrading in industrial clusters? Regional studies, v. 36, n. 9, p. 1017-1027, 2002.

IBGE. Região de influência das cidades. Rio de Janeiro: IBGE, 1993

JACOBS, J. The economy of cities. New York e Toronto: Vintage Books, 1970

KRUGMAN, P. Development, geography and economic theory. Cambridge: MIT Press, 1995.
LIMA, J. P. R. (Coord.) et al. O Pólo Médico do Recife: cadeia de valor, desafios e oportunidades. Recife: Editora Universitária da UFPE, 2004

LÖSCH (1940) apud JOHNSTON, R.; GREGORY, D.; SMITH, D. (Eds.). The dictionary of human geography. [S.1.]: Blackwell, 1994.

LUNDVALL, B-A. National systems of innovation: towards a theory of innovation and interactive learning. London: Pion, 1992.

LUNDVALL, B. Explaining interfirm cooperation and innovation: limits of the transaction-cost approach. In: GRABHER, G. (Ed.) The embedded firm. On the socioeconomics of industrial networks. London: Routledge, 1993. p. $52-64$.

MAILLAT, D. Regional productive systems and innovative milieux. In: OECD/Leed Programme, Networks of enterprises and local development. Competing and co-operating in Local Productive Systems. Paris: OECD Publications, 1996. 
MAILLAT, D. Regional productive systems and innovative milieux.

LEED/OECD Network of enterprises and local development, OECD, Paris, p. 67-80, 1999.

MARSHALL, A. (1890) Princípios de economia. Tratado introdutório. São Paulo: Abril Cultural, 1982. v. I, cap. VIII. (Série Os economistas).

MIGLINO, M. A. P. Inovação: o local importa? Um ensaio sobre os nexos entre inovação e espaço segundo autores contemporâneos. 2002.

Dissertação (Mestrado) -

Departamento de Política Científica e Tecnológica, IG-UNICAMP, Campinas. Mimeografado.

MORGAN, Kevin. The exaggerated death of geography: learning, proximity and territorial innovation systems. Journal of Economic Geography, special issue on "physical and organisation proximity in territorial innovation systems", 2004.

NELSON, R. The sources of economic growth. Cambridge: Harvard University Press, 1996.

PIORE, M. E.; SABEL, C. The second industrial divide: possibilities for prosperity. Nova York: Basic Books, 1984.

PORTER, M. E. The competitive advantage of nations. New York: Free Press, 1990.

PORTER, M. On Competition. Harvard: Harvard Business School Press, 1998.
PORTER, M. Clusters and the new economics of competition. Harvard Business Review, p. 77-90, 1998.

PORTER, M. Cluster profiles. 2004. Disponível em: <http://data.isc. hbs.edu/cp/index.jsp $>$

PORTER, R.; LLOYD-EVANS, $\mathrm{S}$. The city in the developing world. Harlow: Longman, 1998.

POWELL, Walter W.; SMITH-DOERR, Laurel.

Networks and economic life. In: SMELNER, N. J.; SWEDBERT, R. (Ed.). The handbook of Economic Sociology. Princeton: Princeton University Press, 1994.

RICHARDSON, H. W. Regional economics. New York: Praeger Publishers Inc., 1969.

SASSEN, S. The global city: New York, London, Tokyo. Londres: Princeton university Press, 1991.

SCHMITZ, H. Collective efficiency: growth path for small scale industry. Journal of Development Studies, n. 23, p. 9-28, 1995.

SCHMITZ, H.; NADVI, K. Clustering and industrialization: introduction. World development, v. 27 , n. 9 , p. $1503-1514,1999$

SCOTT, A. Metropolis: from the division of labour to urban form. Berkeley: University of California Press, 1988.

SCOTT, A.; STORPER, M. Production, work, territory. The geographical anatomy of industrial capitalism. Boston: Allen and Unwin, 1986.
SICSÚ, A. B. Análise das tendências tecnológicas nas estruturas (planos e seguros de saúde, hospitais, clínicas e laboratórios) do núcleo do Pólo Médico do Recife. In: LIMA, J Policarpo. (Coord.) et al. O Pólo Médico do Recife: cadeia de valor, desafios e oportunidades, Recife: Editora Universitária da UFPE, 2004.

STEINLE, C.; SCHIELE, H.

When do industries cluster? A proposal on how to assess an industry's propensity to concentrate at a single region or nation. Research policy, v. 31, p. $849-858,2002$.

STORPER, M. The Regional World: territorial development in a global economy. Perspectives on Economic Change. London: Guilford Press, 1997.

SUZIGAN, W. Clusters e sistemas locais de inovação: estudos de casos e avaliação da região de campinas. Campinas: Papirus, 1999.

(Texto para discussão).

SUZIGAN, W.; FURTADO, J.; GARCIA, R.; SAMPAIO, S.

Coeficientes de Gini locacionais GL: aplicação à indústria de calçados do Estado de São Paulo. Nova Economia, v. 13, n. 2 , p. 39-60, 2003.

TINOCO, A. Integração ou fragmentação? O impasse gerado pelo fetichismo da desconcentração. Espaço e debates, v. 41, p. 46-65, 2001.
VON THÜNEN (1826) apud JOHNSTON, R.; GREGORY, D.; SMITH, D. (Eds.). The dictionary of human geography. [S.1.]: Blackwell, 1994.

Os autores agradecem os - comentários de Mauro Rocha - Côrtes e Marcelo Pinho e o - apoio da FINEP.

\section{E-mail de contato da autora:}

anafc@ufpe.br

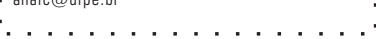

